\title{
11 \\ Man Bac: Regional, Cultural and
Temporal Context
}

\author{
Marc F. Oxenham ${ }^{1}$ and Hirofumi Matsumura ${ }^{2}$ \\ ${ }^{1}$ School of Archaeology and Anthropology, Australian National University \\ ${ }^{2}$ Department of Anatomy, Sapporo Medical University, Japan.
}

One of the most important issues facing us is the interpretation of Man Bac and its placement in a cultural and temporal context. The archaeological context of Man Bac places it firmly within a cultural complex identified as the Phung Nguyen, dated to around 1,800-1,400 BCE (Nguyen et al. 2004). In recent years, this cultural complex has been referred to as either Late neolithic or earliest Bronze Age (Nguyen et al. 2004, Oxenham et al. 2008). The term 'neolithic' has been traditionally used in Southeast Asia to characterise communities with presumed or proven agriculture and pottery, but without metal (Bellwood, 1992: 94). However, the presence or absence of pottery is not necessarily useful by itself in identifying 'the neolithic', with good examples of pottery manufacture by hunter-gatherers in late Pleistocene and early Holocene northeast Asia, including Initial and Early Jomon Japan (Habu, 2004). There was also a lack of pottery in many of the earliest clearly agricultural contexts in many parts of the world, for instance in the Levant (Lev-Yadun et al., 2000), and in Mesoamerica and the Andes (Bellwood 2005). Conversely, the earliest evidence for pottery in South America (c. 6,000 BCE in the lower Amazon and c. $5,000 \mathrm{BCE}$ in northern Columbia) occurred in the absence of agriculture (Bellwood 2005: 158).

In northern Vietnam at least, pottery appeared first among Mid-Holocene hunter-gatherer communities (e.g. Da But, see Patte, 1965), well before any evidence for agriculture. Similarly, the Early Neolithic in China, dating to some $16,000-8,000$ years $\mathrm{BCE}$ and named as such due to the presence of pottery, appears devoid of any clear evidence for agriculture. Furthermore, while clear support for domestication appears in the Middle Neolithic (8,000-5,000 BCE) of the Middle and Lower Yangtze basin, the same time period (still termed the Middle Neolithic) in southern and southwest China lacks evidence for agriculture (Zhang and Hung 2008). It was not until the early phase of the Late Neolithic $(5,000-3,500$ $\mathrm{BCE}$ ) in southern China that clear evidence for pig domestication first occurred (Zhang and Hung 2008:313). During the late phase of the Late Neolithic (3,5002,500 BCE), Zhang and Hung (2008:313-314) regard the Guangxi-Guangdong region (termed Lingnan by Chinese archaeologists) plus Fujian as a recipient of major farming dispersals from the more northerly Middle and Lower Yangtze basin. In the Terminal Neolithic, 2,500-2,000 BCE, 
the number of settlements dramatically increased in the Lingnan-Fujian region and southwest China. Locally, this was the full blossoming of the Neolithic in this area, at a time when regional populations are estimated to have exceeded in size those of the middle and lower Yangtze

Zhang and Hung (2008:314)

The earliest clear material cultural links involving pottery between southern China and northern Vietnam can be seen in the presumed hunter-gatherer archaeological sites attributed to the $\mathrm{Da}$ But and Dingsishan (Phases 1 to 3) cultural complexes in Vietnam and Guangxi respectively (Zhang and Hung 2010). The dating of $\mathrm{Da}$ But and allied sites is problematic, but they are believed to have flourished between 4,500 and 2,500 BCE (see Nguyen 2005). Da But sites are generally characterised by large shell midden deposits, edge ground pebble ('Bacsonian') axes and very coarse cord-marked pottery (Oxenham et al. 2005). The Da But burial practices are unique in northern Vietnam, in that a significant number of the inhumations are tightly flexed squatting burials with limited grave goods, and no pottery (Oxenham 2000). The largest excavated Da But cemetery site is at Con Co Ngua, which included 96 burials that exhibited very low levels of oral disease but a high frequency of serious accidental trauma, possibly related to their hunter-gatherer subsistence activities (Oxenham et al. 2001, Oxenham et al. 2006, Oxenham 2006). The presence of pottery in the Da But complex, and at least one large cemetery, suggests some level of sedentism (Oxenham 2000). As with the convention adopted in China, Vietnamese archaeologists see the $\mathrm{Da}$ But as a "neolithic" culture, ostensibly due to the presence of pottery and edge ground axes. Nguyen et al. (2004) have gone as far as to characterise the Da But as Middle neolithic, and the pre-Bacsonian Hoabinhian period in general, which extends back to at least $16,000 \mathrm{BCE}$, as early neolithic, despite the absence of pottery prior to $\mathrm{Da}$ But and Con Co Ngua.

The value and archaeological meaning of the term "Neolithic" in China and northern Vietnam is thus very unclear, particularly in the context of its use as a form of short-hand for the presence of pottery. The meaning of the term is clearly tested in the use of "Middle Neolithic" to describe clear agricultural communities in the Yangtze Basin on the one hand, and contemporaneous hunter-gatherer communities in southern China on the other (see Zhang and Hung 2008, for instance). In Chinese archaeology this terminological problem stems from the imposition of a rigid chronological framework, based on the better known developments over the last 10,000 years in the Yangtze basin, on to other parts of China that experienced very different cultural and technological developments at very different periods of time. Using this system to characterise the $\mathrm{Da}$ But in Vietnam would lead to it being labelled the Early Phase of the Late neolithic. Man Bac (as part of the Phung Nguyen) would become the Terminal neolithic, even though the Phung Nguyen complex to which it belongs contains the earliest evidence for agriculture and animal domestication in northern Vietnam.

In would seem that the real value of the term "neolithic" lies in its use as a short hand for a major change in human subsistence and associated behaviour, i.e. the development of food production (animal and plant domestication). Pottery by itself is not a good signature for animal and plant domestication, as pointed out above. 
"Neolithic" as a chronological marker, let alone a behavioural indicator, has limited, if any value, in northern Vietnam, or southern China for that matter. If pottery using cultures associated with otherwise hunter-gatherer economies require some form of special signification, perhaps it would be better to use a term without profound agricultural connotations - "Pre-Neolithic Pottery using Cultures" (PNPC) may be a value-free substitute.

Much of the discussion so far has aimed to secure an appropriate regional, cultural and temporal context for Man Bac. It can be seen that Man Bac was part of the agriculturally driven demographic expansion that occurred in what is now southern China between 2,500 and 2,000 BCE. The Da But complex represents the southern periphery of the expansion of Late Pre-Neolithic Pottery using Cultures (PNPC), as represented by Dingsishan, that seem to have emerged in northern Vietnam between 4,500-4,000 BCE. The Phung Nguyen, including Man Bac, represents the southern periphery of a subsequent expansion of Neolithic (here meaning food producing) communities originating in the geographical region of southern China.

The agricultural developments, and their dating, in southern China prior to the emergence of the Phung Nguyen appear to provide a good framework or model for understanding sites like Man Bac, which is dated to between 1,500-1,800 BCE. But do the findings of this monograph support such a model?

Several bioarchaeological lines of evidence from Man Bac support the view that the site is representative of a demographic expansion from southern China into northern Vietnam some time shortly after 2,000 BCE. In Chapter 2 it was argued that Man Bac appeared to be a reasonably representative sample in terms of its demographic profile. Moreover, a relatively high level of fertility was evident, consistent with an earlier investigation by Bellwood and Oxenham (2008), with high JA and MCM values indicative of high population growth. High levels of fertility, and evidence for population growth, are consistent with the model for demographically driven expansion from southern China, involving the arrival of new immigrant food producers in the Man Bac region.

Cranio-morphometric analyses (Chapter 3) demonstrate: (1) a significant morphological, and by extension genetic, gulf between late Pleistocene to mid Holocene Pre-Neolithic Pottery using Cultures, such as those from Da But and Con Co Ngua, and later Metal Period populations in northern Vietnam; (2) that Man Bac is morphometrically mosaic, and by implication genetically heterogeneous, with some individuals showing the earlier Hoabinhian/Bacsonian morphology, others being indistinguishable from the Metal Period morphology, and some a hybrid between the two. Qualitative and quantitative analyses of the teeth (Chapter 5) revealed a slightly different, albeit not entirely inconsistent, picture to the craniomorphometrics. The greater dental size variance, relative to Metal Period samples, suggests a greater genetic heterogeneity in the Man Bac sample. Moreover, the close affinity of the Man Bac to Metal Period samples in terms of odontometric proportions, but the intermediate position of Man Bac between earlier Da But and Hoabinhian samples on the one hand, and later Metal Period series on the other, speaks to the highly variable nature of the Man Bac population. The most parsimonious explanation for such morphological and genetic heterogeneity is that the Man Bac population was undergoing a major and rather rapid genetic 
transition. It would seem clear the source of this transition is to be found within a population of food producing immigrants into the region.

Interestingly, the analysis of Man Bac cranial non-metric traits (Chapter 4) did not find the sample particularly heterogeneous, but rather found that Man Bac was mostly closely affiliated with Metal Period and modern Southeast Asians, as well as with the Chinese Weidun Neolithic sample from the lower Yangtze, dated to between 4,000-3,000 BCE. This finding is consistent with Zhang and Hung's (2008) suggestion that there was a major dispersal of farming communities from the lower Yangtze south into the Lingnan-Fujian region between 3,500-2,500 BCE. It is from such immigrant populations that the subsequent demographic expansion into northern Vietnam occurred. Why Dodo's (Chapter 4) non-metric analysis does not indicate the level of heterogeneity found by Matsumura (Chapters 3 and 5) is unclear. It may be simply that a greater contribution of immigrant genes existed in the Man Bac sample than was indicated by Matsumura's analyses. Shinoda's ancient mDNA analysis (Chapter 8) clearly points to a major genetic input to the Man Bac community from a more northerly source, although genetic heterogeneity rather than a predominantly modern Southeast Asian or East Asian signal is suggested. Whatever the reason, Dodo's analysis is still consistent with the general model for the expansion of farming communities from southern China into northern Vietnam after 2,000 BCE.

Two final strands of evidence were dealt with in this monograph: human palaeohealth and zooarchaeology. Earlier work comparing the palaeohealth of the Da But complex (Con Co Ngua specifically) and a Metal Period series from northern Vietnam suggested an increase in infectious disease and/or a decline in immunocompetence in the latter period, arguably associated with agricultural activities (Oxenham et al. 2005). This is consistent with bioarchaeological studies globally, that show a generalised trend of declining health with the adoption and/or intensification of agriculture (see an earlier summary in Larsen 1995). However, Southeast Asian assemblages do not, for the most part, follow the trend of declining oral health seen in many other parts of the world with the adoption/intensification of agriculture (see Oxenham et al. 2006). The level and patterning of infectious disease in Man Bac has not been assessed, although oral and physiological health has. Man Bac exhibits the highest rate of caries seen in any Southeast Asian assemblage, albeit only marginally greater than that observed in the contemporary site of Khok Phanom Di in Thailand. Moreover, very high levels of physiological stress are indicated by the elevated frequencies of LEH and cribra orbitalia. Given the apparent caries-neutral effects of a rice diet (Tayles et al. 2009), a cereal apparently absent at Man Bac, but present at Khok Phanom Di, it is intriguing that two of the earliest neolithic assemblages in the region also exhibit the highest rates of caries, by far. In addition to the likely effects of elevated levels of fertility on oral health in both series (see Chapter 2), it is possible that root crops were an important staple at both sites. Tayles (1999) has suggested the possible availability of tubers and bananas at Khok Phanom Di, while Zhang and Hung (2010) suggest that tubers played a significant role, in addition to rice agriculture, in Neolithic subsistence in Lingnan-Fujian. If tubers, rather than rice, played a significant role in subsistence during the beginnings of food production in Southeast Asia, only to be replaced by rice as agriculture became more established, this may explain the 
elevated rates of caries in the earliest agricultural populations in the region.

But are tubers particularly cariogenic foodstuffs? Despite being inferred to be cariogenic (e.g. see Turner 1979), little is known of the cariogenic or prophylactic properties of root crops such as taro (see Toverud et al. 1952:485). Modified tubers such as poi (fermented taro) have been implicated in elevated rates of caries in Hawaii (Miller 1974), but we have been unable to locate experimental evidence to confirm this. Nonetheless, some processed tubers, cassava flour at least, are believed to be cariogenic (Rosalen et al. 1997). A study of variation in caries incidence in Papua New Guinea suggests that the particular mineral contents of foods such as sago and taro are most important in the prevalence of caries (Barmes et al. 1970). Unfortunately, Man Bac is silent on the presence or otherwise of root crops such as taro, and clearly more research is needed to determine the effect, positive or negative, that tubers have on dental health.

The final set of biological evidence comes from the animal remains (Chapter 9), which showed not only that food production in the form of pig domestication occurred at Man Bac, but that pigs contributed significantly in terms of a terrestrial food source. The view of Sawada et al. that we are seeing the initial stages of pig domestication at Man Bac is intriguing. It could be that limited stocks of domesticated immigrant pigs were being supplemented by locally domesticated indigenous pigs. Apart from pig domestication, Sawada and colleagues also point out that the Man Bac community targeted a range of taxa in their hunting activities, albeit taxonomically impoverished in comparison to earlier huntergatherer communities in the region. Whatever the role of animal and plant domestication in terms of subsistence contributions at Man Bac, the diverse range of animals and habitats exploited, highlights the importance of such activities in their day to day lives. Moreover, the fish remains (see Chapter 10) also indicate a considerable variety of exploited habitats, with an apparent emphasis on targeting very large fish with a sophisticated fishing technology.

The habitat diversity and breadth of hunting and fishing technologies and behaviours suggested by the mammalian and fish remains is intriguing. Not only is a very good knowledge of the local environment indicated, but a long history of hunting and fishing behaviours is suggested. How do we reconcile the model of rapid demographic expansion of agricultural communities from Lingnan-Fujian into northern Vietnam, with a community such as Man Bac, retaining sophisticated hunting and fishing skills that also required an intimate local knowledge of the environment? The biologically mosaic nature of the Man Bac human community provides an answer. Man Bac is clearly representative of interaction, possibly at many levels, of in-coming food producing migrants and an indigenous population. The new migrants brought domesticated plants and pigs to the table, while the indigenous populations with whom they were integrating likely brought a sophisticated and intimate knowledge of the local environment, including an ancient tradition of hunting and fishing. Man Bac is one of those rare archaeological instances of a community in transition, both in terms of its human genetic makeup, and with respect to major behavioural shifts in subsistence lifeways. 


\section{LITERATURE CITED}

Barmes DE, Adkins BL, and Schamschula RG. 1970. Etiology of caries in Papua-New Guinea: associations in soil, food and water. Bull Wld Hlth Org 43:769-784.

Bellwood P. (1992) Southeast Asia before history. In: Tarling N., editor. The Cambridge History of Southeast Asia: Volume One Frome early Times to c. 1800. Cambridge University Press: Cambridge. pp. 55-136.

Bellwood P. 2005. First farmers; The Origins of Agricultural Societies. Blackwell; Main St, Maiden, MA.

Bellwood P, Oxenham M. 2008. The expansions of farming societies and the role of the Neolithic Demographic Transition. In: Bocquet-Appel J-P, Bar-Yosef O, editors. The Neolithic Demographic Transition and its Consequences. Dordrecht: Springer.

Habu J. (2004) Ancient Jomon of Japan. Cambridge University Press; Cambridge.

Larsen CS. 1995. Biological changes in human populations with agriculture. Annual Review of Anthropology 24:185-213.

Lev-Yadun, S., A. Gopher \& S. Abbo. 2000.The cradle of agriculture. Science 288:16021603.

Miller CD. 1974. The influence of foods and food habits upon the stature and teeth of the ancient Hawaiians. In CE Snow (edited). Early Hawaiians;an Initial Study of Skeletal Remains from Mokapu, Oahu. Lexington, KY: University of Kentucky Press, pp. 167175.

Nguyen KS, Pham MH, and Tong TT. 2004. Northern Vietnam from the Neolithic to the Han Period. In I Glover and P Bellwood (editors) Southeast Asia from Prehistory to History, London and New York: Routledge Curzon, p:177-201.

Nguyen V. 2005. The Da But Culture evidence for cultural development in Vietnam during the middle Holocene. Indo-Pacific Prehistory Association Bulletin 25(3):89-93.

Oxenham MF. 2000. Health and Behaviour During the Mid-Holocene and Metal Period of Northern Viet Nam. Unpublished PhD Thesis, Northern territory University, Darwin, NT, Australia.

Oxenham MF. 2006. Biological responses to change in prehistoric Vietnam. Asian Perspectives 45:212-239.

Oxenham MF, Walters I, Nguyen LC and Nguyen KT. 2001. Case Studies in Ancient Trauma: Mid-Holocene through Metal Periods in Northern Viet Nam. In Henneberg M, and Kilgariff J, editors. The Causes and Effects of Biological Variation. Australasian Society for Human Biology: University of Adelaide, p. 83-102.

Oxenham MF, Nguyen KT, Nguyen LC. 2005. Skeletal evidence for the emergence of infectious disease in bronze and iron age northern Vietnam. Am J Phys Anthropol 126:359-376.

Oxenham MF, Nguyen LC, Nguyen KT. 2006. The oral health consequences of the adoption and intensification of agriculture in Southeast Asia. In: Oxenham M, Tayles N, editors. Bioarchaeology of Southeast Asia. Cambridge: Cambridge University Press. p 263-289.

Oxenham MF, Matsumura H, Domett K, Nguyen KT, Nguyen KD, Nguyen LC, Huffer D, Muller S. 2008. Health and the experience of childhood in late Neolithic Vietnam. Asian Perspectives 47:190-209.

Patte E. 1965. Les ossements du kjokkenmodding de Da But. Bulletin du Service Ethnologie de Indochine 10: 1-87.

Rosalen PL, Volpato MC, and Ruenis AP. 1997. Cariogenic [correction of Carcinogenic] potential of a typical cassava flour from the Amazonian region of Brazil. Indian J Dent Res. 8(3):72-6.

Tayles N. 1999. The excavation of Khok Phanom Di: a prehistoric site in Central Thailand. Volume IV: the people. The Society of Antiquaries of London: Oxbow Books.

Tayles N, Domett K, Halcrow S. 2009. Can dental caries be interpreted as evidence of 
farming? The Asian experience. In: Kope T, Meyer G, Alt KW, editors. Comparative Dental Morphology. Basel: Karger. p 162-166.

Toverud G, Finn SB, Cox GJ, Bodecker CF, and JH Shaw. 1952. A Survey of the Literature of Dental Caries. National Academy of Sciences: Washington D.C.

Turner CG (II). 1979. Dental anthropological indications of agriculture among the Jomon people of central Japan. Am J Phys Anthropol 51(4):619-635.

Zhang C, and Hung HC. 2008. The Neolithic of Southern China-Origin, Development, and Dispersal. Asian Perspectives 47(2): 299-329.

Zhang C, and Hung HC. 2010. The emergence of agriculture in Southern China. Antiquity 84: 11-25. 